\title{
Resection of colorectal liver metastases after second-line chemotherapy: is it worthwhile? A LiverMetSurvey analysis of 6415 patients
}

\author{
René Adam ${ }^{\mathrm{a}, *, 1}$, Bin $\mathrm{Yi}^{\mathrm{a}, \mathrm{b}, 1}$, Pasquale $\mathrm{F}$. Innominato ${ }^{\mathrm{c}, 2,3}$, \\ Eduardo Barroso $^{\mathrm{d}}$, Christophe Laurent ${ }^{\mathrm{e}}$, Felice Giuliante ${ }^{\mathrm{f}}$, \\ Lorenzo Capussotti $^{\mathrm{g}}$, Réal Lapointe ${ }^{\mathrm{h}}$, Jean-Marc Regimbeau ${ }^{\mathrm{i}}$, \\ Santiago Lopez-Ben ${ }^{j}$, Helena Isoniemi ${ }^{k}$, Catherine Hubert ${ }^{1}$, \\ Jen-Kou Lin ${ }^{\mathrm{m}, \mathrm{n}}$, Thomas Gruenberger ${ }^{\circ}$, Dominique Elias ${ }^{\mathrm{p}}$, \\ Oleg G. Skipenko ${ }^{\mathrm{q}}$, Alfredo Guglielmi ${ }^{\mathrm{r}}$ the LiverMetSurvey International \\ Contributing Centers
}

a Hepatobiliary Center, AP-HP Hôpital Paul Brousse, Université Paris-Sud, Inserm U935, Villejuif, France

${ }^{\mathrm{b}}$ Eastern Hepatobiliary Surgery HospitallNational Liver Cancer Center, Second Military Medical University, Shanghai, China

${ }^{\mathrm{c}}$ Department of Oncology, AP-HP Hôpital Paul Brousse, Université Paris-Sud, Inserm U935, Villejuif, France

d Department of HPB Surgery and Transplantation, Curry Cabral Hospital, Lisbon, Portugal

${ }^{\mathrm{e}}$ Department of Digestive Surgery, Hôpital Saint André, Bordeaux, France

${ }^{\mathrm{f}}$ Hepatobiliary Surgery Unit, Agostino Gemelli Hospital, Catholic University of the Sacred Heart, Rome, Italy

${ }^{g}$ Department of HPB and Digestive Surgery, Ospedale Mauriziano Umberto I, Turin, Italy

${ }^{\mathrm{h}}$ HPB Surgery and Transplantation Unit, Hôpital Saint-Luc, Centre Hospitalier de l'Université de Montréal, Montréal, Canada

${ }^{i}$ Department of Oncology and Digestive Surgery, CHU Amiens-Picardie, Amiens, France

${ }^{\mathrm{j}}$ Hepatobiliary and Pancreatic Surgery Unit, Department of Surgery, Dr. Josep Trueta Hospital, IdlBGi, Girona, Spain

${ }^{\mathrm{k}}$ Department of Transplantation and Liver Surgery, Helsinki University Hospital, Helsinki, Finland

${ }^{1}$ Unit of HPB Surgery, Cliniques Universitaires Saint-Luc, Université Catholique de Louvain, Brussels, Belgium

${ }^{\mathrm{m}}$ Division of Colon \& Rectal Surgery, Department of Surgery, Taipei Veterans General Hospital, Taipei, Taiwan

${ }^{\mathrm{n}}$ School of Medicine, National Yang-Ming University, Taipei, Taiwan

${ }^{\circ}$ Department of Surgery, Medical University of Vienna, General Hospital, Vienna, Austria

${ }^{\mathrm{p}}$ Department of Oncologic Surgery, Institut Gustave Roussy, Villejuif, France

${ }^{\mathrm{q}}$ Research Center of Surgery, Russian Academy of Medical Science, Moscow, Russia

${ }^{\mathrm{r}}$ Division of Surgery A, Department of Surgery, GB Rossi Hospital, University of Verona, Verona, Italy

Received 29 November 2016; received in revised form 20 February 2017; accepted 5 March 2017

Available online 10 April 2017

\footnotetext{
* Corresponding author: Hepatobiliary Center, AP-HP Hôpital Paul Brousse, Université Paris-Sud, Inserm U935, 12 Avenue Paul Vaillant Couturier, 94804 Villejuif, France. Fax: +331455938 57.

E-mail address: rene.adam@aphp.fr (R. Adam).

1 These authors contributed equally to this work.

${ }^{2}$ Current address: Cancer Chronotherapy Unit, Cancer Research Centre, Warwick Medical School, Warwick University, Coventry, Warwickshire, UK.

${ }^{3}$ Current address: Queen Elizabeth Hospital Birmingham, University Hospitals Birmingham NHS Foundation Trust, Birmingham, UK.
} 


\section{KEYWORDS}

Colorectal cancer;

Liver metastasis;

Preoperative

chemotherapy;

Second line;

Hepatectomy

\section{Introduction}

Liver resection is the only treatment that currently offers a chance of long-term survival to patients with colorectal liver metastases (CLM). For patients with primarily resectable CLM, especially those with advanced, multiple or borderline resectable disease, perioperative systemic chemotherapy has been given to increase their long-term survival by reducing the risk of recurrence after resection. However, the majority of patients with CLM are not initial candidates for hepatic resection. Without conversion chemotherapy, surgical resection is not possible for $70 \%-80 \%$ of those patients. Encouragingly, the combination of systemic chemotherapy and liver surgery could switch a significant proportion of patients from a palliative to a potentially curative situation, with a reported postoperative 5-year survival of $33 \%$ after rescue surgery [1-3]. Recently, an international panel of multidisciplinary experts developed recommendations for the management of patients with CLM, indicating that preoperative treatment to induce resectability should be as short as possible, and that postoperative chemotherapy (POCT) should continue with the same protocol when preoperatively effective [4].

Failure to respond to first-line therapy has frequently predicted poor response rates of subsequent lines of therapy [5-7]. For patients where disease control is the goal, patients should proceed to second-line therapy when there is evidence of disease progression, or toxicity of the first-line [8]. However, the combination of second-line systemic chemotherapy (for neoadjuvant or conversion purpose) with CLM resection has been scarcely described. Its impact on survival is not yet demonstrated, and what kind of patients can really benefit from the resection is so far unknown. In this study, we aimed to analyse the impact of the CLM resection after second-line treatment, in terms of overall survival (OS) and disease-free survival (DFS) in a large international dataset, and to find out the predictive factors of outcomes for such patients. The survival data were also compared to that of the CLM resection following first-line chemotherapy, in the same oncosurgical teams, although the two cohorts were not rigorously comparable.

\section{Patients and methods}

\subsection{Patient selection}

LiverMetSurvey is a prospective international internetbased registry, collecting and regularly updating clinical data from all consecutive patients undergoing surgery for CLM, and was designed to assess the efficacy of multimodality treatment of CLM [3]. It accounted on 25th December 2015, with 243 individual patients from 313 institutions worldwide (70 countries). In this study, the data of 6415 consecutive patients were retrospectively analysed. Between January 2005 and June 2013, 5624 patients underwent resection after first-line chemotherapy (group 1) and 791 patients following second-line chemotherapy (group 2), respectively.

Patient eligibility criteria included the completion of hepatic resection with intent to resect all the metastases, irrespective of the initial resectability of CLM and of the 
need for specific combined techniques to optimise resectability after first- or second-line preoperative chemotherapy (PCT). In this study, we defined a secondline regimen when the first-line cytotoxic backbone had changed, or when a biological agent had been added. Patients receiving second-line because of intolerable toxicity were included because this situation is not rare in clinical practice, although toxicity does not reflect the tumour response to chemotherapy. The initially unresectable patients in group 1 were classified into subgroup 1, and such patients in group 2 into subgroup 2 for additional subgroup analyses.

Patients, on whom an R2 resection was performed, although considered surgically unsatisfactory, were included in the analysis since we adopted an intent-totreat policy on such patients, as in real-life situations.

\subsection{Preoperative management}

Generally, the response to chemotherapy was evaluated every four cycles with computed tomography (CT) according to the Response Evaluation Criteria in Solid Tumours Criteria (RECIST) [9]. In each centre, patients were evaluated from referral by the same local multidisciplinary team, who determined when to start a chemotherapy with neoadjuvant or conversion intent, when to perform liver resection and when to switch to second-line PCT, in case of progression, or insufficient response (stable disease or partial response unable to allow complete or safe resection) or in case of unacceptable toxicity on first-line regimen. Generally, as an accepted clinical practice, for the patients with potentially resectable CLM but with advanced, multiple or borderline resectable disease, neoadjuvant chemotherapy was proposed with the intent to increase survival.

\subsection{Hepatic resection}

The overall policy of hepatectomy was carried out with the attempt of a complete resection of all lesions by anatomic or wedge resection, sparing the largest amount of hepatic parenchyma but providing as much as possible a safe margin of normal parenchyma from the tumour. Radiofrequency ablation was combined with hepatectomy whenever appropriate in treating unresectable remnant lesions limited in number $(\leq 3)$ and size $(<3 \mathrm{~cm})$. Two-stage hepatectomy was reserved for the patients whose disease was deemed unresectable by a single procedure. Other combined techniques including portal vein embolisation were also employed.

\subsection{Postoperative chemotherapy}

POCT was routinely used after hepatectomy, with the same regimen when preoperatively effective.

\subsection{Follow-up}

Patients were usually followed one month later after the resection, then every 3-6 months according to the centre policy, with tumour markers (carcinoembryonic antigen and carbohydrate antigen 19.9), clinical examination, thoracic and hepatic imaging (ultrasound and/or CT and/ or magnetic resonance imaging). Repeat resection of intrahepatic recurrence or extrahepatic disease was performed by the local surgical team when potentially curative.

\subsection{Statistical analysis}

Survival was calculated from CLM diagnosis and from hepatectomy to death or to the last available follow-up. Patient survival probabilities were determined by the life-table method and compared in the log-rank test. A multivariate Cox proportional hazard model with a likelihood ratio test was used to identify predictive factors for OS (from CLM diagnosis) and DFS. According to RECIST, tumour responses after first- or second-line chemotherapy were classified into either progression or no progression for multivariate model. Statistical analyses were performed with SAS software version 9.1.3 (SAS Institute Inc., Cary, NC, USA).

\section{Results}

Overall, 5624 patients $(87.7 \%)$ and 791 patients $(12.3 \%)$ received CLM resection after 1 and 2 PCT lines (group 1 and group 2), respectively. The incidences of CLM resection by year following 1 and 2 PCT lines are shown in Supplementary Fig. A1.

\subsection{Patient and tumour characteristics}

The clinical characteristics of the study population are shown in Table 1, together with comparisons between groups, and between initially unresectable subgroups.

\subsection{Chemotherapy data}

Supplementary Table A1 presents the PCT regimens used in the two groups. Doublet regimens were administered to $63.4 \%$ of the patients in second-line, triplet regimens were used to $3.6 \%$, and monoclonal antibodies were given to $33.0 \%$ of these patients. Compared to the first-line PCT in group 1, the second-line PCT in group 2 included more often irinotecan-based regimen and combination with cetuximab or panitumumab.

In group 2, patients received a median of six (interquartile range [IQR], 4-9) cycles of first-line chemotherapy. The causes for switching to second-line were disease progression $(22.2 \%)$, stable disease $(22.7 \%)$, insufficient partial response $(48.1 \%)$ or intolerable toxicity 
Table 1

Comparison of clinical features of the study population.

\begin{tabular}{|c|c|c|c|c|c|c|}
\hline \multirow[t]{2}{*}{ Characteristics } & \multicolumn{3}{|c|}{ Whole population } & \multicolumn{3}{|c|}{ Initially unresectable } \\
\hline & $\begin{array}{l}1 \text { PCT line } \\
(n=5624)\end{array}$ & $\begin{array}{l}2 \text { PCT lines } \\
(n=791)\end{array}$ & $P$-value & $\begin{array}{l}1 \text { PCT line } \\
(n=1637)\end{array}$ & $\begin{array}{l}2 \text { PCT lines } \\
(n=290)\end{array}$ & $P$-value \\
\hline Female, \% & 39.2 & 34.9 & 0.019 & 39.5 & 34.5 & NS \\
\hline Age, mean (SD), year & $61.6(10.7)$ & $61.4(10.6)$ & NS & $60.5(11.1)$ & $60.4(10.2)$ & NS \\
\hline \multicolumn{7}{|l|}{ Primary tumour localisation, $\%$} \\
\hline Left including sigmoid & 42.6 & 48.3 & \multirow[t]{5}{*}{0.049} & 47.0 & 53.8 & \multirow[t]{5}{*}{ NS } \\
\hline Rectum & 32.5 & 29.7 & & 29.6 & 26.4 & \\
\hline Right & 18.0 & 16.4 & & 16.6 & 14.6 & \\
\hline Transverse & 3.5 & 2.7 & & 4.0 & 2.4 & \\
\hline Multiple localisations & 3.3 & 2.9 & & 2.7 & 2.8 & \\
\hline Metastatic primary lymph nodes, $\%$ & 67.8 & 68.4 & NS & 66.7 & 66.4 & NS \\
\hline Concomitant extrahepatic disease, $\%$ & 12.2 & 16.7 & $<0.001$ & 14.8 & 21.7 & 0.003 \\
\hline $\begin{array}{l}\text { Interval between disease diagnosis and liver } \\
\text { metastasis occurrence, mean (SD), months }\end{array}$ & $7.1(18)$ & $5.5(12.3)$ & 0.002 & $5.9(17.6)$ & $4.7(10.4)$ & NS \\
\hline \multicolumn{7}{|l|}{ No. of liver metastasis at diagnosis, $\%$} \\
\hline $1-3$ & 69.7 & 62.9 & \multirow{3}{*}{$<0.001$} & 49.0 & 46.7 & \multirow{3}{*}{ NS } \\
\hline $4-7$ & 21.9 & 25.7 & & 30.1 & 30.3 & \\
\hline$>7$ & 8.4 & 11.3 & & 20.9 & 23.0 & \\
\hline Metastasis at diagnosis $\leq 30 \mathrm{~mm}, \%$ & 43.5 & 38.7 & 0.023 & 34.0 & 28.5 & NS \\
\hline \multicolumn{7}{|l|}{ Liver metastases, $\%$} \\
\hline Synchronous & 70.9 & 73.5 & NS & 77.2 & 77.0 & \multirow[t]{3}{*}{ NS } \\
\hline Bilateral localisation & 46.9 & 54.1 & $<0.001$ & 68.0 & 67.7 & \\
\hline Initially unresectable & 32.9 & 41.8 & $<0.001$ & 100.0 & 100.0 & \\
\hline \multicolumn{7}{|l|}{ Main causes of non-resectability, $\%$} \\
\hline Number of metastases & - & - & \multirow[t]{5}{*}{-} & 43.7 & 50.8 & \multirow[t]{5}{*}{ NS } \\
\hline Size of metastases & - & - & & 18.4 & 15.2 & \\
\hline Vascular ill location & - & - & & 17.5 & 13.6 & \\
\hline Extrahepatic disease & - & - & & 9.9 & 11.4 & \\
\hline Others & - & - & & 10.5 & 9.1 & \\
\hline \multicolumn{7}{|l|}{ Preoperative chemotherapy cycles } \\
\hline $1-6$ cycles, $\%$ & 62.9 & 17.6 & $<0.001$ & 49.8 & 12.6 & $<0.001$ \\
\hline No., median [IQR] & $6[4-8]$ & $12[8-16]$ & $<0.001$ & $7[5-10]$ & $13[9-18]$ & $<0.001$ \\
\hline \multicolumn{7}{|l|}{ Response to PCT last-line, \% } \\
\hline Complete response & 5.4 & 5.0 & \multirow[t]{4}{*}{$<0.001$} & 3.9 & 4.7 & \multirow[t]{4}{*}{$<0.001$} \\
\hline Partial response & 69.0 & 61.5 & & 81.2 & 66.1 & \\
\hline Stable disease & 19.3 & 25.1 & & 11.0 & 22.6 & \\
\hline Progression & 6.2 & 8.4 & & 3.9 & 6.6 & \\
\hline Limited hepatectomy ( $<3$ segments), $\%$ & 38.4 & 33.0 & 0.004 & 31.4 & 26.7 & NS \\
\hline $\mathrm{R} 0+\mathrm{R} 1$ liver resection, $\%$ & 88.1 & 82.8 & $<0.001$ & 76.0 & 72.7 & NS \\
\hline Hepatectomy not globally curative, $\%$ & 20.6 & 26.1 & $<0.001$ & 35.9 & 38.4 & NS \\
\hline Combined techniques, $\%$ & 28.1 & 37.8 & $<0.001$ & 56.0 & 47.2 & 0.006 \\
\hline Portal vein embolisation, \% & 14.1 & 23.8 & $<0.001$ & 24.9 & 35.3 & $<0.001$ \\
\hline Radiofrequency ablation, $\%$ & 11.3 & 13.4 & NS & 15.4 & 15.4 & NS \\
\hline Cryotherapy, \% & 0.1 & 0 & NS & 0.1 & 0 & NS \\
\hline Two-stage hepatectomy, \% & 11.2 & 14.5 & 0.008 & 21.7 & 23.5 & NS \\
\hline Only one hepatectomy, \% & 83.0 & 79.4 & $<0.001$ & 79.3 & 74.4 & 0.004 \\
\hline No. of hepatectomies/year $\geq 50, \%$ & 45.3 & 54.7 & $<0.001$ & 36.7 & 49.3 & $<0.001$ \\
\hline POCT, $\%$ & 58.3 & 58.2 & NS & 57.8 & 56.6 & NS \\
\hline Cycles, median [IQR] & $6[4-8]$ & $6[4-9]$ & NS & $6[4-8]$ & $6[3-12]$ & NS \\
\hline 90-d postoperative mortality, $\%$ & 2.7 & 2.4 & NS & 3.9 & 4.3 & NS \\
\hline Postoperative complications, $\%$ & 29.9 & 33.5 & 0.044 & 35.0 & 38.7 & NS \\
\hline
\end{tabular}

PCT, preoperative chemotherapy; SD, standard deviation; IQR, interquartile range; POCT, postoperative chemotherapy; NS, not significant.

(7.0\%). Progression or intolerable toxicity was the accepted reason for non-operating patients after first-line chemotherapy. In case of stable disease or partial response, the main consideration was better disease control before surgery for initially resectable patients or adequate conversion to allow complete and safe resection for initially unresectable patients. In second-line, these patients received a median of five $(\mathrm{IQR}, 3-8)$ preoperative cycles of therapy. Furthermore, $58.2 \%$ of group 2 patients received POCT (second-line regimen), and 9.5\% received later a third-line for relapse. Conversely, $58.3 \%$ of group 1 patients received POCT (first-line regimen), 5.3\% received later second-line for relapse and $1.2 \%$ a third-line.

In subgroup 2, patients received a median of six (IQR, 4-11) cycles of first-line chemotherapy with $21.5 \%$ progression and $56.9 \%$ insufficient objective 
response. After a median of six (IQR, 3-9) cycles of second-line, this subgroup experienced $6.6 \%$ progression and $70.8 \%$ objective response $(P<0.001)$.

\subsection{Mortality and morbidity}

After hepatectomy, the 90 -d mortality was $2.4 \%$ in group 2 versus $2.7 \%$ in group $1(P=0.618)$, and the morbidity was $33.5 \%$ versus $29.9 \%$, respectively $(P=0.044)$. For the initially unresectable patients, the mortality was similar between the subgroups and so was the morbidity (Table 1).

\subsection{Overall survival}

After a mean follow-up of 30.1 months, in group 2 $(n=777)$ and group $1(n=5456)$, median OS after diagnosis was 58.6 months $(95 \%$ confidence interval, 52.0-63.2 months) versus 58.9 months (56.0-60.9), 3year OS rate was $76 \%(72 \%-79 \%)$ versus $71 \%(70 \%-$ $73 \%)$ and 5 -year OS was $49 \%(43 \%-54 \%)$ versus $49 \%$ $(47 \%-51 \%)$, respectively $(P=0.32$; Fig. 1 A) $)$ After the first hepatectomy, in group $2(n=785)$ and group 1 $(n=5567)$, median OS was $41.4(39.2-46.8)$ versus 49.0 months $(46.5-51.5), 3$-year OS was $60 \%(55 \%-65 \%)$ versus $62 \%(60 \%-64 \%)$ and 5 -year OS was $35 \%(29 \%-$ $42 \%)$ versus $43 \%(41 \%-45 \%)$, respectively $(P=0.049$; Fig. 1B).

For patients initially unresectable, no statistical difference appeared in OS after diagnosis or after the first hepatectomy (Supplementary Figs. A2 and A3A) between the subgroups of patients resected after first-line and second-line conversion chemotherapy.

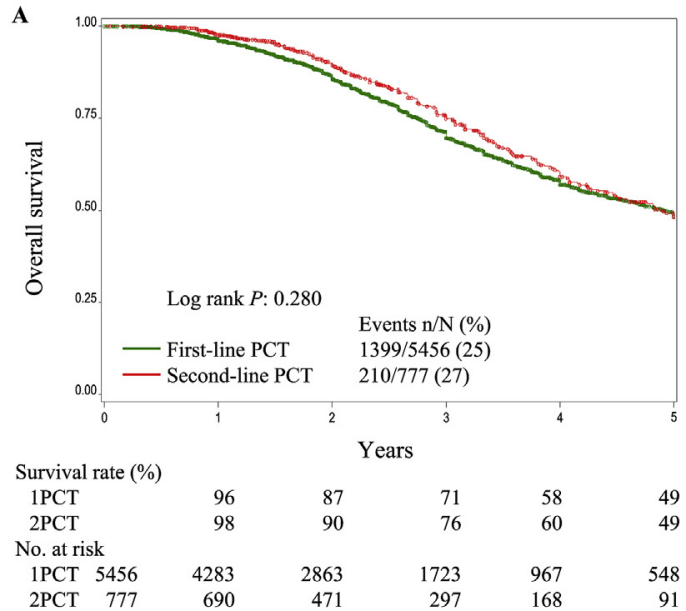

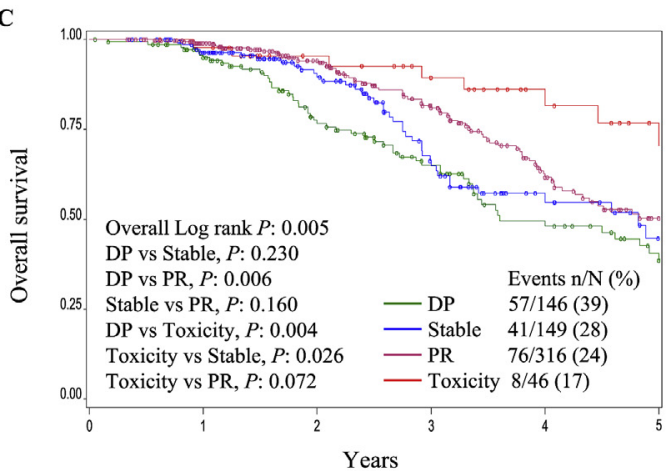

C

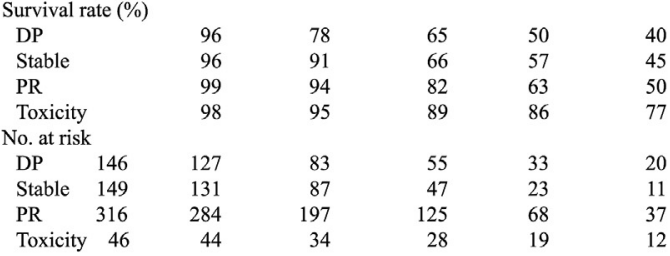

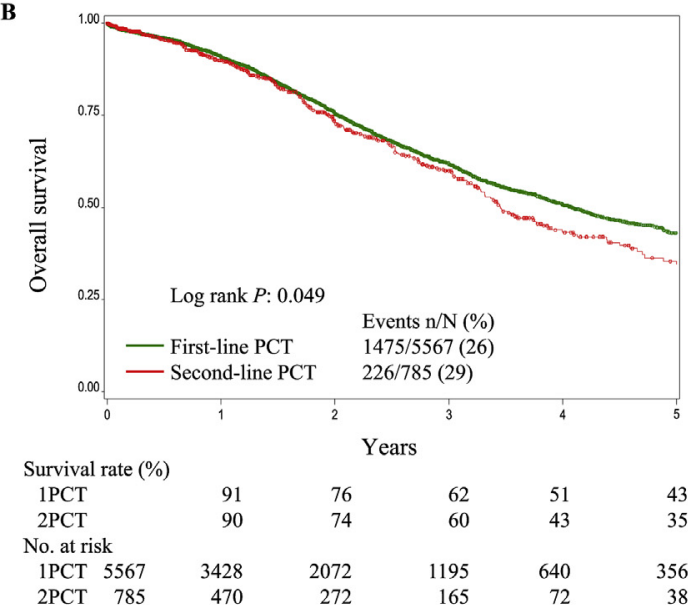

D

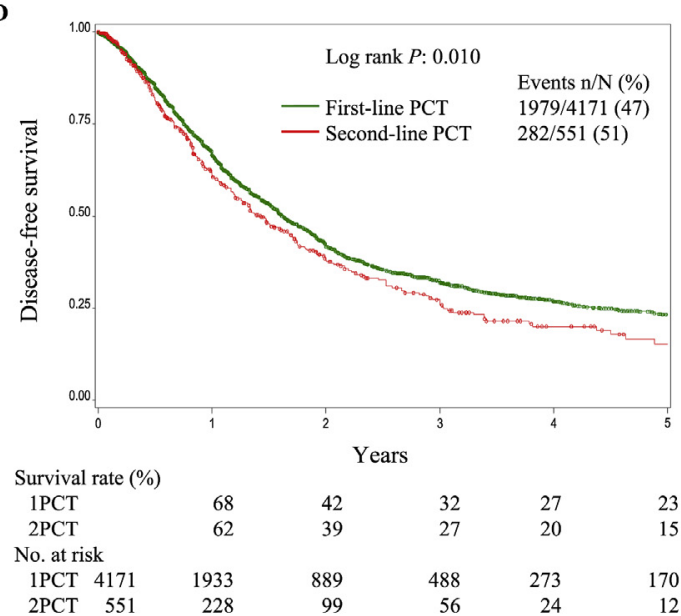

Fig. 1. OS and DFS of CLM patients received liver resection following PCT. OS (A) after diagnosis of CLM resected after PCT; OS (B) and DFS (D) after first hepatectomy of CLM after PCT; OS (C) after metastatic diagnosis of CLM resected after 2nd-line PCT according to cause for chemotherapy change. OS, overall survival; DFS, disease-free survival; CLM, colorectal liver metastases; PCT, preoperative chemotherapy; DP, disease progression; PR, partial response. 
Regarding the impact of the reasons leading to a second-line regimen, OS of progression was similar to that of stable disease but lower compared to that of insufficient partial response or toxicity. Toxicity seemed to be associated with a higher OS than stable disease but not than partial response. No survival difference existed between stable disease and partial response (Fig. 1C).

\subsection{Disease-free survival}

Median, 3-year and 5-year DFS after first macroscopically complete hepatectomy were statistically lower in group 2 (17.2 months, $27 \%$ and $15 \% ; n=551)$ than those in group 1 (19.4 months, $32 \%$ and $23 \% ; n=4171$; $P=0.01$; Fig. 1D). For initially unresectable patients, no statistical difference in DFS was observed between subgroup 2 and subgroup 1 (median, 3- and 5-year: 18.1 months, $28 \%$ and $14 \%$ versus 19.7 months, $32 \%$ and $22 \% ; P=0.09$; Supplementary Fig. A3B).

Concerning the impact of the different causes of second-line inclusion, no statistical difference in DFS was observed (data not shown).

\subsection{Analysis of predictive factors}

\subsubsection{Overall survival}

By multivariate analysis, five factors were independently associated with decreased OS (Table 2). Progressive disease on first-line chemotherapy was associated with worse OS after diagnosis at univariate but not at multivariate analysis, in the studied second-line setting (Fig. 1C). For subgroup 2, in the multivariate model, four independent factors were associated with worse OS
(Table 2). The separate number $(\leq 6$ or $>6)$ of cycles received in first- or second-line did not impact OS in group 2 nor in its unresectable subset (subgroup 2).

\subsubsection{Disease-free survival}

Among group 2 patients with R0/R1 liver resection, the multivariate analysis showed that metastatic lymph nodes, synchronous and bilateral metastases were associated with decreased DFS. Progression on first-line chemotherapy was not predictive for shorter DFS. In this model for subgroup 2 patients, three factors associated with decreased DFS were bilateral metastases, no POCT and radiofrequency combined with hepatectomy (Table 3).

\section{Discussion}

In this study, we observed, in a large international and prospective database, that the outcomes of patients with CLM eventually undergoing resection after second-line PCT were mostly similar to those obtained after firstline PCT, although these two cohorts were not strictly comparable because disease was more extensive in the former. Indeed, not surprisingly, these patients had a statistically heavier tumour burden, a poorer response to treatment and more complex surgical treatments, compared to the patients resected after first-line. From first-line to second-line, the switch offered a better tumour control to these patients, allowing a significantly decreased progression rate from $22.2 \%$ to $8.4 \%$ and an increased objective response rate from $55.1 \%$ to $66.5 \%$. Thus, surgery was offered with more stringent criteria of tumour response to patients after second-line

Table 2

Analysis of OS after metastasis diagnosis in 2 PCT lines patients and its initially unresectable subgroup.

\begin{tabular}{|c|c|c|c|c|c|c|c|c|c|c|}
\hline \multirow[t]{3}{*}{ Risk factors } & \multicolumn{5}{|c|}{ All patients with 2 PCT lines $(n=777)$} & \multicolumn{5}{|c|}{ Initially unresectable patients with 2 PCT lines $(n=283)$} \\
\hline & \multirow[t]{2}{*}{3 years } & \multirow[t]{2}{*}{5 years } & \multirow{2}{*}{$\frac{\text { Univariate }}{P \text {-value }}$} & \multicolumn{2}{|c|}{ Multivariate } & \multirow[t]{2}{*}{3 years } & \multirow[t]{2}{*}{5 years } & \multirow{2}{*}{$\frac{\text { Univariate }}{P \text {-value }}$} & \multicolumn{2}{|c|}{ Multivariate } \\
\hline & & & & $P$-value & HR $(95 \% \mathrm{CI})$ & & & & $P$-value & $\operatorname{HR}(95 \% \mathrm{CI})$ \\
\hline \multicolumn{11}{|c|}{ Metastatic primary lymph nodes } \\
\hline Yes & $73 \%$ & $41 \%$ & 0.002 & 0.018 & $1.54(1.08-2.19)$ & $69 \%$ & $44 \%$ & 0.440 & - & \\
\hline No & $83 \%$ & $63 \%$ & & & & $76 \%$ & $48 \%$ & & & \\
\hline \multicolumn{11}{|c|}{ Concomitant extrahepatic disease } \\
\hline Yes & $65 \%$ & $35 \%$ & $<0.001$ & 0.016 & $1.58(1.09-2.29)$ & $62 \%$ & $34 \%$ & 0.009 & 0.005 & $2.10(1.25-3.51)$ \\
\hline No & $78 \%$ & $52 \%$ & & & & $74 \%$ & $48 \%$ & & & \\
\hline \multicolumn{11}{|c|}{ Second-line tumour progression } \\
\hline Yes & $69 \%$ & $45 \%$ & 0.120 & 0.016 & $1.75(1.11-2.77)$ & $65 \%$ & $55 \%$ & 0.870 & - & \\
\hline No & $76 \%$ & $49 \%$ & & & & $72 \%$ & $44 \%$ & & & \\
\hline \multicolumn{11}{|c|}{ Liver curative resection } \\
\hline R2 & $56 \%$ & $25 \%$ & $<0.001$ & $<0.001$ & $2.72(1.86-3.96)$ & $53 \%$ & $27 \%$ & 0.011 & 0.002 & $2.65(1.44-4.86)$ \\
\hline $\mathrm{R} 0 / \mathrm{R} 1$ & $81 \%$ & $54 \%$ & & & & $78 \%$ & $51 \%$ & & & \\
\hline \multicolumn{11}{|c|}{ No. of hepatectomies/year } \\
\hline$<50$ & $72 \%$ & $43 \%$ & $<0.001$ & 0.002 & $1.67(1.20-2.33)$ & $68 \%$ & $39 \%$ & 0.003 & 0.004 & $2.49(1.35-4.62)$ \\
\hline$\geq 50$ & $79 \%$ & $55 \%$ & & & & $75 \%$ & $52 \%$ & & & \\
\hline \multicolumn{11}{|c|}{ Postoperative chemotherapy } \\
\hline No & $70 \%$ & $47 \%$ & 0.290 & - & & $66 \%$ & $35 \%$ & 0.009 & $<0.001$ & $2.30(1.42-3.72)$ \\
\hline Yes & $79 \%$ & $49 \%$ & & & & $80 \%$ & $55 \%$ & & & \\
\hline
\end{tabular}

PCT, preoperative chemotherapy; HR, hazard ratio; CI, confidence interval; OS, overall survival. 
Table 3

Analysis of DFS in the R0/R1 2 PCT lines patients and its initially unresectable subgroup.

\begin{tabular}{|c|c|c|c|c|c|c|c|c|c|c|}
\hline \multirow[t]{3}{*}{ Risk factors } & \multicolumn{5}{|c|}{ All patients with 2 PCT lines $(n=551)$} & \multicolumn{5}{|c|}{ Initially unresectable patients with 2 PCT lines $(n=167)$} \\
\hline & \multirow[t]{2}{*}{3 years } & \multirow[t]{2}{*}{5 years } & \multirow{2}{*}{$\frac{\text { Univariate }}{P \text {-value }}$} & \multicolumn{2}{|c|}{ Multivariate } & \multirow[t]{2}{*}{3 years } & \multirow[t]{2}{*}{5 years } & \multirow{2}{*}{$\frac{\text { Univariate }}{P \text {-value }}$} & \multicolumn{2}{|c|}{ Multivariate } \\
\hline & & & & $P$-value & $\operatorname{HR}(95 \% \mathrm{CI})$ & & & & $P$-value & $\operatorname{HR}(95 \% \mathrm{CI})$ \\
\hline \multicolumn{11}{|c|}{ Metastatic primary lymph nodes } \\
\hline Yes & $23 \%$ & $15 \%$ & 0.020 & 0.020 & $1.39(1.05-1.82)$ & $24 \%$ & $9 \%$ & 0.220 & - & \\
\hline No & $40 \%$ & $19 \%$ & & & & $36 \%$ & $18 \%$ & & & \\
\hline \multicolumn{11}{|c|}{ Synchronous metastasis } \\
\hline Yes & $25 \%$ & $17 \%$ & 0.033 & 0.043 & $1.36(1.01-1.82)$ & $26 \%$ & $17 \%$ & 0.600 & - & \\
\hline No (metachronous) & $34 \%$ & $14 \%$ & & & & $29 \%$ & $9 \%$ & & & \\
\hline \multicolumn{11}{|l|}{ Bilateral localisation } \\
\hline Yes & $21 \%$ & $13 \%$ & 0.002 & 0.018 & $1.36(1.05-1.75)$ & $21 \%$ & - & 0.024 & 0.047 & $1.60(1.01-2.55)$ \\
\hline No & $34 \%$ & $17 \%$ & & & & $34 \%$ & $24 \%$ & & & \\
\hline \multicolumn{11}{|c|}{ Radiofrequency ablation } \\
\hline Yes & $20 \%$ & $13 \%$ & 0.009 & NS & & $13 \%$ & - & $<0.001$ & 0.008 & $2.09(1.21-3.61)$ \\
\hline No & $30 \%$ & $16 \%$ & & & & $30 \%$ & $18 \%$ & & & \\
\hline \multicolumn{11}{|c|}{ Postoperative chemotherapy } \\
\hline Yes & $29 \%$ & $16 \%$ & 0.026 & NS & & $32 \%$ & $16 \%$ & 0.010 & 0.024 & $1.68(1.07-2.62)$ \\
\hline No & $20 \%$ & $10 \%$ & & & & $15 \%$ & - & & & \\
\hline
\end{tabular}

PCT, preoperative chemotherapy; HR, hazard ratio; CI, confidence interval; NS, not significant; DFS, disease-free survival.

chemotherapy. Despite less favourable tumour characteristics in such patients, OS from CLM diagnosis was similar, whether hepatectomy was performed after firstor second-line chemotherapy. However, surgery after second-line was associated with a decreased OS and DFS after hepatectomy in comparison to first-line.

Usually patients with CLM receiving second-line chemotherapy and then hepatectomy are expected to have a poorer prognosis, hence the rationale to perform resection is questioned. A retrospective study reported a 5-year OS after hepatectomy following second-line of $22 \%$ and a 5-year DFS of only $11 \%$ [10]. In our multicentre study, however, such patients (group 2) displayed relatively better results. After hepatectomy, the median and 5-year figures were 41.4 months and $35 \%$ for OS and 17.2 months and $15 \%$ for DFS, respectively. Moreover, the median and 5-year OS after diagnosis were 58.6 months and $49 \%$, respectively, not significantly different from those observed in group 1. One recent meta-analysis has shown a respective median and 5-year OS of 39.6 months and $37.0 \%$ in patients with CLM resected after PCT, most of which were administered as front-line regimen [11]. The survival rates in our patients are consistent with these results.

Compared to chemotherapy alone, a median OS of 58.6 months from diagnosis or 41.4 months from hepatectomy following a second-line regimen is quite promising for patients failing a first-line regimen. A recent Phase III trial reported a median OS from randomisation of 13.5 months in patients receiving secondline therapy of aflibercept added to an irinotecan-based regimen [12]. Another trial combining bevacizumab with irinotecan- or oxaliplatin-based second-line reported a median OS from the start of first-line of 23.9 months [13]. In this context, our results support the indication of
CLM resection even after second-line regimen, whenever technically possible.

Furthermore, even though the risk of surgery after second-line chemotherapy was expected to be increased owing to the larger number of cycles and the heavier tumour load, we found that the 90-d mortality in group 2 was similar to that in group $1(<3 \%)$. These results are also consistent with recent data reporting a median 30 -d mortality of $2.8 \%$ in CLM treated with hepatectomy irrespective of PCT delivery [14]. Compared to that of group 1, the risk appeared nevertheless acceptable, with no increased mortality and with more frequent but tolerable morbidity (33.5\% versus $29.9 \%$ ), further endorsing resection whenever indicated after second-line PCT.

In addition, our rather large sample size allowed the identification of prognostic factors, allowing an even more refined selection of patients in second-line PCT concerning the indication of surgery (Table 2). In the multivariate model of group 2, metastatic primary lymph nodes, concomitant extrahepatic disease, and R2 liver resection were independently associated with a decreased OS. However, the required surgical procedures including major hepatectomy, two-stage hepatectomy or repeat hepatectomies did not emerge as independent prognostic factors. As expected, tumour progression on second-line emerged independently as a negative factor for OS in multivariate model. This suggests that control of the disease, particularly for secondline PCT patients, is essential before surgery to improve outcome, as previously reported by our team in a study on patients with $>3$ metastases [15]. Additionally, the reason for discontinuation of first-line and switching to second-line was believed to be relevant to the outcome, especially progression as a surrogate for a more biologically resistant and aggressive disease. 
Discontinuation for unacceptable toxicity is a common reason for quitting a clinical trial. Even though disease progression is the most frequent cause of discontinuation, basically every oncologist has had experience of switch to second-line for poor tolerance. Therefore, we included such patients receiving second-line because of toxicity. In this study, the causes were exhibited as not only progression $(22.2 \%)$ but stable disease, insufficient partial response or intolerable toxicity $(7.0 \%)$. However, the occurrence of progression during the first-line did not independently impact on OS after diagnosis, on the condition that the disease was favourably controlled by second-line PCT, and patients achieved to be resected. This finding proposes an effective treatment of secondline even when the disease appeared chemo-resistant to front-line.

Multivariate analysis showed that metastatic primary lymph nodes, synchronous and bilateral metastases were significantly associated with a decreased DFS in group 2 patients. To our knowledge, no study has yet reported prognostic factors of DFS on such patients. Among all patients with resected CLM, reported DFS predictors include primary lymph nodes, number of liver metastases, resection margin and CA19-9 after hepatectomy [16-18]. We found that the type of regimen, the use of biological agents, the number of cycles and a tumour progression on PCT were not associated with DFS. Moreover, initially unresectable patients did not suffer a poorer OS or DFS than those initially resectable, although the definition of unresectability could have differed from one centre to another.

Among initially unresectable patients with CLM resected after a second-line regimen, encouragingly, OS or DFS was comparable to its counterpart among the patients after first-line. The 3-year OS after diagnosis of $45 \%$ in this study compares favourably to that of $10 \%-$ $44 \%$ reported in series of conversion therapies with targeted agents or of hepatic arterial infusion after failure of previous regimens [19-21].

The current study has obviously some limitations. It is a retrospective analysis of surgery-based database with evitable selection bias. By definition the patients who eventually did not undergo resection were not evaluated in LiverMetSurvey. Also, the chemotherapy regimens were decided at the convenience of local oncologists and were consequently diverse, and the treatment algorithms were non-standardised. But on the other hand, this study presents the 'real life' results of a large international cohort, acknowledging that the evaluation of such an approach would be difficult in small series of individual centres and unpractical to be designed within a randomised clinical trial. Furthermore, the heterogeneity of PCT regimens used allowed a comparison among them. Thus, in accordance with previous [7] and more recent [22,23] reports, neither the cytotoxic backbone (oxaliplatin or irinotecan), nor the targeted agent (anti-VEGF or anti-EGFR) used for second-line in this study impacted on clinical outcomes, provided that they were active in downsizing the disease and achieving resectability.

In conclusion, our study demonstrated that CLM resection after second-line chemotherapy, once it is achieved with favourable disease control, even with lesions deemed initially as non-resectable, could offer an estimated survival close to that after first-line and better than what is proved by concomitant data on chemotherapy alone, without a higher risk of perioperative mortality. Hence, we propose liver surgery on the patients whose liver metastases are sufficiently downsized to envisage resection, not only after front-line but also after active salvage chemotherapy.

\section{Funding}

This research did not receive any specific grant from funding agencies in the public, commercial or not-forprofit sectors.

\section{Conflict of interest statement}

R. Adam received honoraria from Merck, Amgen and Sanofi for oral presentation in congress symposia. LiverMetSurvey benefits from an unrestricted grant from Sanofi.

\section{Acknowledgements}

The authors thank Valérie Cailliez for helping with statistical analysis, Youssef Yataghene for helping with the manuscript and all the contributing centres for collecting the data.

\section{Appendix A. Supplementary data}

Supplementary data related to this article can be found at http://dx.doi.org/10.1016/j.ejca.2017.03.009.

\section{References}

[1] Adam R, Delvart V, Pascal G, Valeanu A, Castaing D, Azoulay D, et al. Rescue surgery for unresectable colorectal liver metastases downstaged by chemotherapy: a model to predict long-term survival. Ann Surg 2004;240:644-57.

[2] Giacchetti S, Itzhaki M, Gruia G, Adam R, Zidani R, Kunstlinger F, et al. Long-term survival of patients with unresectable colorectal cancer liver metastases following infusional chemotherapy with 5-fluorouracil, leucovorin, oxaliplatin and surgery. Ann Oncol 1999;10:663-9.

[3] LiverMetSurvey: International registry of patients operated for colorectal liver metastasis. Available at: http://www. livermetsurvey.org.

[4] Adam R, De Gramont A, Figueras J, Guthrie A, Kokudo N, Kunstlinger F, et al. The oncosurgery approach to managing liver metastases from colorectal cancer: a multidisciplinary international consensus. Oncologist 2012;17:1225-39. 
[5] Ahlgren JD, Trocki O, Gullo JJ, Goldberg R, Muir WA, Sisk R, et al. Protracted infusion of 5-FU with weekly low-dose cisplatin as second-line therapy in patients with metastatic colorectal cancer who have failed 5-FU monotherapy. Cancer Invest 1991;9:27-33.

[6] Bertrand M, Doroshow JH, Multhauf P, Blayney DW, Carr BI, Cecchi G, et al. High-dose continuous infusion folinic acid and bolus 5-fluorouracil in patients with advanced colorectal cancer: a phase II study. J Clin Oncol 1986;4:1058-61.

[7] Tournigand C, André T, Achille E, Lledo G, Flesh M, MeryMignard D, et al. FOLFIRI followed by FOLFOX6 or the reverse sequence in advanced colorectal cancer: a randomized GERCOR study. J Clin Oncol 2004;22:229-37.

[8] Van Cutsem E, Cervantes A, Adam R, Sobrero A, Van Krieken JH, Aderka D, et al. ESMO consensus guidelines for the management of patients with metastatic colorectal cancer. Ann Oncol 2016;27:1386-422.

[9] Therasse P, Arbuck SG, Eisenhauer EA, Wanders J, Kaplan RS, Rubinstein L, et al. New guidelines to evaluate the response to treatment in solid tumors. European Organization for Research and Treatment of Cancer, National Cancer Institute of the United States, National Cancer Institute of Canada. J Natl Cancer Inst 2000;92:205-16.

[10] Brouquet A, Overman MJ, Kopetz S, Maru DM, Loyer EM, Andreou A, et al. Is resection of colorectal liver metastases after a second-line chemotherapy regimen justified? Cancer 2011;117: 4484-92.

[11] Kanas GP, Taylor A, Primrose JN, Langeberg WJ, Kelsh MA, Mowat FS, et al. Survival after liver resection in metastatic colorectal cancer: review and meta-analysis of prognostic factors. Clin Epidemiol 2012;4:283-301.

[12] Van Cutsem E, Tabernero J, Lakomy R, Prenen H, Prausová J, Macarulla T, et al. Addition of aflibercept to fluorouracil, leucovorin, and irinotecan improves survival in a phase III randomized trial in patients with metastatic colorectal cancer previously treated with an oxaliplatin-based regimen. J Clin Oncol 2012;30:3499-506.

[13] Bennouna J, Sastre J, Arnold D, Österlund P, Greil R, Van Cutsem E, et al. Continuation of bevacizumab after first progression in metastatic colorectal cancer (ML18147): a randomised phase 3 trial. Lancet Oncol 2013;14:29-37.

[14] Simmonds PC, Primrose JN, Colquitt JL, Garden OJ, Poston GJ, Rees M. Surgical resection of hepatic metastases from colorectal cancer: a systematic review of published studies. Br J Cancer 2006; 94:982-99.
[15] Adam R, Pascal G, Castaing D, Azoulay D, Delvart V, Paule B, et al. Tumor progression while on chemotherapy: a contraindication to liver resection for multiple colorectal metastases? Ann Surg 2004;240:1052-61.

[16] Hamady ZZ, Cameron IC, Wyatt J, Prasad RK, Toogood GJ, Lodge JP. Resection margin in patients undergoing hepatectomy for colorectal liver metastasis: a critical appraisal of the $1 \mathrm{~cm}$ rule. Eur J Surg Oncol 2006;32:557-63.

[17] Muratore A, Ribero D, Zimmitti G, Mellano A, Langella S, Capussotti L. Resection margin and recurrence-free survival after liver resection of colorectal metastases. Ann Surg Oncol 2010;17: 1324-9.

[18] Inoue Y, Hayashi M, Komeda K, Masubuchi S, Yamamoto M, Yamana $\mathrm{H}$, et al. Resection margin with anatomic or nonanatomic hepatectomy for liver metastasis from colorectal cancer. J Gastrointest Surg 2012;16:1171-80.

[19] Adam R, Aloia T, Lévi F, Wicherts DA, de Haas RJ, Paule B, et al. Hepatic resection after rescue cetuximab treatment for colorectal liver metastases previously refractory to conventional systemic therapy. J Clin Oncol 2007;25:4593-602.

[20] Boige V, Malka D, Elias D, Castaing M, De Baere T, Goere D, et al. Hepatic arterial infusion of oxaliplatin and intravenous LV5FU2 in unresectable liver metastases from colorectal cancer after systemic chemotherapy failure. Ann Surg Oncol 2008;15: 219-26.

[21] D'Angelica MI, Correa-Gallego C, Paty PB, Cercek A, Gewirtz AN, Chou JF, et al. Phase II trial of hepatic artery infusional and systemic chemotherapy for patients with unresectable hepatic metastases from colorectal cancer: conversion to resection and long-term outcomes. Ann Surg 2015;261: $353-60$.

[22] Venook AP, Niedzwiecki D, Lenz H-J, Innocenti F, Mahoney M, O’Neil B, et al. CALGB/SWOG 80405: phase III trial of irinotecan/5-FU/leucovorin (FOLFIRI) or oxaliplatin/5FU/leucovorin (mFOLFOX6) with bevacizumab or cetuximab for patients with KRAS wild-type untreated metastatic adenocarcinoma of the colon or rectum (MCRC). ASCO Annual Meeting. J Clin Oncol 2014;32:5s (suppl; abstr LBA3).

[23] Venook AP, Niedzwiecki D, Lenz H-J, Mahoney M, Innocenti F, O'Neil B, et al. CALGB/SWOG 80405: analysis of patients undergoing surgery as part of treatment strategy. ESMO Annual Meeting. Ann Oncol 2014;25:1-41 (LBA10). 